\title{
Therapeutics
}

\section{Review: a home-like birth environment has beneficial effects on labour and delivery}

Hodnett ED. Home-like versus conventional institutional settings for birth. Cochrane Database Syst Rev 2002;(1):CD000012 (latest version 13 Jul 2001).

\section{QUESTION: In women at low risk for obstetric complications, what are the effects of a home-like birth environment compared with those of a conventional labour ward on labour and birth outcomes?}

\section{Data sources}

Studies were identified by using the search strategy developed for the Cochrane Pregnancy and Childbirth Group, which included searching Medline and the Cochrane Controlled Trials Register, and by handsearching 38 relevant journal titles.

\section{Study selection}

Studies were selected if they were randomised controlled trials (RCTs) or quasi-RCTs that compared a homelike institutional birth setting with a conventional institutional birth setting in low risk pregnant women.

\section{Data extraction}

Data were extracted on methodological quality, including allocation concealment procedure, patient characteristics, birthing centre characteristics, and outcomes. Outcomes were intrapartum medical interventions, intrapartum and postpartum complications, type of delivery, perinatal mortality, feeding practices and problems, neonatal health outcomes, and adjustment to mothering.

\section{Main results}

5 RCTs and 1 quasi-RCT ( $\mathrm{n}=8677$ ) were included. $19 \%$ to $77 \%$ of women allocated to a home-like birth setting were transferred to conventional care before or during labour. Women who gave birth in the home-like setting had less use of pain medication during labour, were less likely to be immobile during labour, had fewer fetal heart rate abnormalities, had fewer operative deliveries, and were less dissatisfied with their care than were women in the conventional labour ward setting (table). Groups did not differ for discontinuation of breast feeding at 8 weeks (table). A trend toward higher perinatal mortality was seen in the home-like setting $\{\mathrm{p}=0.066\}^{*}$ (table).

\section{Conclusion}

In women at low risk for obstetric complications, giving birth in a home-like birth environment is associated with less analgesia use, operative delivery, and fetal abnormalities and greater satisfaction with care. *p Value calculated from data in article.

\section{COMMENTARY} malities. operative deliveries, and abnormal fetal heart rate tracings. is recognised early and dealt with effectively. alternative but warrants further attention, specifically to perinatal mortality.

2 Anderson RE, Anderson DA.J Nurse Midwifery 1999;44:30-5.

3 Gilbert RE, Tookey PA. BMJ 1999;319:483-7. bbimainpage.html).
Source of funding: $n o$ external funding.

For correspondence: Professor E D Hodnett, University of Toronto, Toronto, Ontario, Canada.

ellen.hodnett@ utoronto.ca.

Home-like birth environments, in which low risk women are looked after mainly by professional midwives, have shown such benefits as greater maternal satisfaction ${ }^{1}$ and decreases augmentation, use of analgesia, operative deliveries, and fetal heart rate abnor-

In the review by Hodnett, the results show that when women are looked after in home-like birth environments they are more likely to be mobile during the first stage of labour and more likely to deliver in an upright or semirecumbent position. These 2 factors may contribute to the substantial decrease in augmentation rates, use of analgesia,

The interventions in this review can be applied to most developed and developing countries. Analgesia (epidural and spinal) or operative delivery are an enormous cost burden to health service providers, and it has been shown that the average uncomplicated vaginal birth costs $68 \%$ less in a home setting than in a hospital. ${ }^{2}$

The concern is that the delay in operative deliveries or delay of interventions may contribute to an increase in perinatal mortality. Although a trend existed toward increased perinatal mortality, the incidence was low and within normal limits. ${ }^{3}$ It is important that healthcare providers giving care to women in home-like birth environments continue to observe the women during labour and birth so that fetal compromise

The use of home-like birth environments for low risk women has beneficial effects on parturients. The results of the review by Hodnett support the goals of the Better Births Initiative. ${ }^{4}$ Financial shortages are major problems in developing countries. Introducing home-like birth environments with good clinical care could be a cost-effective healthcare

Cheryl Nikodem, DCur Tembisa Hospital Effective Care Research Unit Midrand South Africa

Longworth L, Ratcliffe J, Boulton M. Health Soc Care Community 2001;9:404-13

4 Effective Health Care Alliance Programme. Better births initiative (www.liv.ac.uk/lstm/

Home-like birth setting v conventional labour ward $\dagger$

\begin{tabular}{|c|c|c|c|c|c|}
\hline \multirow[b]{2}{*}{ Outcomes } & \multirow[b]{2}{*}{$\begin{array}{l}\text { Number of } \\
\text { trials }\end{array}$} & \multicolumn{2}{|c|}{ Weighted event rates } & \multirow[b]{2}{*}{ RRR $(95 \%$ Cl) } & \multirow[b]{2}{*}{ NNT (Cl) } \\
\hline & & $\begin{array}{l}\text { Home-like } \\
\text { setting }\end{array}$ & $\begin{array}{l}\text { Conventional } \\
\text { setting }\end{array}$ & & \\
\hline Any intrapartum analgesia & 4 & $69 \%$ & $75 \%$ & $8 \%(5$ to 10$)$ & 18 (13 to 27$)$ \\
\hline Immobility during labour & 1 & $31 \%$ & $39 \%$ & $19 \%(10$ to 27$)$ & 14 (10 to 28$)$ \\
\hline FHR abnormality & 2 & $19 \%$ & $25 \%$ & $23 \%(15$ to 30$)$ & 18 (13 to 29$)$ \\
\hline Operative delivery & 5 & $15.2 \%$ & $17.4 \%$ & $12 \%(3$ to 20$)$ & 46 (27 to 200$)$ \\
\hline Dissatisfaction with care & 2 & $27 \%$ & $70 \%$ & $62 \%(50$ to 71$)$ & $3(2$ to 3$)$ \\
\hline \multirow[t]{2}{*}{ Stopped breast feeding within 6 to 8 weeks } & 2 & $1.26 \%$ & $1.26 \%$ & $1 \%(-60$ to 149$)$ & Not significant \\
\hline & & & & RRI (Cl) & NNH \\
\hline Perinatal mortality & 4 & $0.68 \%$ & $0.38 \%$ & $82 \%(-3$ to 243$)$ & Not significant \\
\hline
\end{tabular}

†FHR = fetal heart rate. Other abbreviations defined in glossary; RRR, RRI, NNT, NNH, and Cl calculated from data in article using fixed effects. 